\title{
Role of Malocclusion and Craniofacial Morphology in Obstructive Sleep Apnea
}

\author{
Harpreet Singh ${ }^{1}$, Poonam Sharma ${ }^{2}$, Pranav Kapoor ${ }^{3}$, Raj K Maurya ${ }^{4}$
}

\begin{abstract}
Being one of the most pervasive disorder with far-reaching adverse health implications, understanding the etiology of obstructive sleep apnea (OSA) in relation to craniofacial morphology and malocclusion is critical with regards to rational treatment planning, management, and longterm stability. The principal aim of this article is to present an invaluable insight into the role of malocclusion in the genesis of OSA by reviewing the orthodontic and sleep medicine literature pertaining to pediatric and adult OSA populations. The potential mechanisms underlying the association of malocclusion and OSA are also discussed.
\end{abstract}

Keywords: Dentofacial deformities, Malocclusion, Orthodontics.

Indian Journal of Sleep Medicine (2019): 10.5005/jp-journals-10069-0033

\section{INTRODUCTION}

$\mathrm{N}$ ormal sleep is a complex, critical physiological activity significantly affecting all aspects of an individual's existence. ${ }^{1}$ In sleep disorders, disruption of normal sleep architecture usually results in nocturnal hypoxemia, frequent arousals during sleep, excessive daytime somnolence and can lead to systemic disease. ${ }^{1,2}$ The most common and significant presentation of sleep-disordered breathing (SDB) is OSA that constitutes a significant proportion (84\%) of all SDB cases and has myriad implications beyond disrupted sleep. ${ }^{3}$ OSA is a chronic, progressive, multifactorial and potentially life-threatening sleep disorder in which recurrent episodes of partial or complete collapse of the upper airway occur during sleep in the presence of active inspiratory or ventilatory effort. ${ }^{4,5}$ It has been reported that an estimated $1.2-5.7 \%$ of children are affected by OSA with a greater prevalence in boys than girls. ${ }^{6}$ Myriad population studies across different ethnicities and countries report similar adult OSA prevalence rates in the range of $3-7.5 \%$ in males and $2-3 \%$ in females, despite the differences in demographics, craniofacial structures and obesity patterns in various populations. ${ }^{7}$ Having been often overlooked and underdiagnosed for many decades, OSA is now being widely recognized as a pervasive medical disorder having far-reaching adverse medical and psychological implications. ${ }^{8}$

Myriad physio-anatomic factors contributing to the pathophysiology of OSA include upper airway anatomy, upper airway resistance, upper airway muscle activity during sleep and central control of respiration. ${ }^{9}$ Additionally, significant role of craniofacial factors involving a spectrum of craniofacial abnormalities, and obesity has been implicated in pathogenesis of OSA. ${ }^{10}$ Of all the factors, structural factors related to craniofacial bony anatomies, such as bimaxillary retrusion (retropositioning of the maxilla and mandible), mandibular retrognathia and micrognathia, microgenia, mandibular hypoplasia, shorter maxillary length, and high-arch narrow palate are being increasingly acknowledged as predisposing factors in etiopathogenesis of OSA. ${ }^{7}$

Understanding the etiology of OSA is critical with regards to treatment planning, management, and long-term stability. The predominant association of OSA with obesity as a major risk factor has been well-documented in the literature. The purpose of this article is to provide a concise overview of the role of malocclusion in the development of OSA by reviewing the orthodontic and
${ }^{1}$ Associate Professor, ${ }^{2}$ Professor and Head, ${ }^{3}$ Professor, ${ }^{4}$ Assistant Professor

${ }^{1-3}$ Department of Orthodontics and Dentofacial Orthopedics, ESIC Dental College and Hospital, New Delhi, India

${ }^{4}$ Army Dental Centre (Research and Referral), New Delhi, India

Corresponding Author: Raj K Maurya, Assistant Professor, Army Dental Centre (Research and Referral), New Delhi, India, Phone: 7000139308, e-mail: bracedbyraj@gmail.com

How to cite this article: Singh $\mathrm{H}$, Sharma P, Kapoor P, Maurya RK. Role of Malocclusion and Craniofacial Morphology in Obstructive Sleep Apnea. Indian Sleep Med 2019;14(1):10-17

Source of support: Nil

Conflict of interest: None

sleep medicine literature pertaining to pediatric and adult OSA populations. The potential mechanisms underlying the association of malocclusion and OSA are also discussed.

\section{Etiopathogenesis of OSA in relation to Craniofacial Morphology and Malocclusion}

The importance of the role of maxillofacial malformation and malocclusion in OSA has attracted greater attention only in the recent past ${ }^{11}$ Malocclusion is a type of maxillofacial anomaly that has been ascribed as a major cause for breathing through the mouth. Mouth breathing during sleep is often associated with backward shifting of the tongue with its base periodically contacting the posterior pharyngeal wall and causing partial occlusion of the upper airway in the retropalatal and retroglossal regions. ${ }^{12}$ Presence of nasal obstruction in association with maxillary constriction also contributes to high nasal resistance, lateral narrowing of the upper oral cavity and altered tongue posture, consequently narrowing the retroglossal airway in OSA patients. ${ }^{13}$ Relaxation of the genioglossal and mentalis muscle and hypotonicity of the surrounding musculature during sleep progression can easily cause glossoptosis of the collapsed upper airway in humans lying in a supine position. ${ }^{14}$ More so with increased overjet (i.e., the horizontal overlap between upper and lower incisor teeth when the opposing posterior teeth are in contact), the inability of the patients to attain normal lip closure further compounds the problem. ${ }^{15}$

In spite of being a serious problem with important public health implications in a developing country like India with limited health

(C) The Author(s). 20190pen Access This article is distributed under the terms of the Creative Commons Attribution 4.0 International License (http://creativecommons. org/licenses/by/4.0/), which permits unrestricted use, distribution, and non-commercial reproduction in any medium, provided you give appropriate credit to the original author(s) and the source, provide a link to the Creative Commons license, and indicate if changes were made. The Creative Commons Public Domain Dedication waiver (http://creativecommons.org/publicdomain/zero/1.0/) applies to the data made available in this article, unless otherwise stated. 
resources, the role of malocclusion in OSA is most often overlooked, thus rendering the problem/condition being often underdiagnosed and untreated. In such a scenario, the role of orthodontist trained to monitor growth assumes great importance in the early evaluation, formulation of the individualized treatment plan, and the institution of appropriate treatment.

\section{Diagnostic Tools for Malocclusion Assessment as Related to Obstructive Sleep Apnea}

A thorough functional, positional, and structural assessment of the dentofacial pattern, including the assessment of the pharyngeal structures, is indispensable with the orthodontic diagnosis and treatment planning. Diagnosis of hard and soft tissue anatomic abnormalities contributing to narrowing or obstruction of the pharyngeal airway during sleep should be based on comprehensive clinical examination, lateral cephalometric analysis, digital photographic analysis, photogrammetry and study model analysis, all of which aid in the quantitative evaluation of facial proportions, profiles, and malocclusion. Three-dimensional volumetric reconstructions and analyses using computed tomography (CT) scans and $\mathrm{MRI}$ also prove invaluable in a comprehensive assessment of craniofacial morphology in OSA. ${ }^{7}$

\section{Malocclusion as a Risk Factor for OSA in children}

Ikävalko et al. ${ }^{16}$ reported that altered craniofacial morphology is a predisposing risk factor for the development of OSA in some children. Morphologic features related to a long and narrow face such as dolichofacial pattern, high mandibular plane angle, increased lower anterior face height, narrow high-arch palate, and severe maxillary and mandibular crowding, in conjunction with mandibular retrognathia and a convex profile are the most commonly reported dentofacial characteristics in pediatric OSA patients. ${ }^{17-19}$ An example of a pediatric non-obese patient with Class II malocclusion and severe anterior open bite, displaying signs of OSA is illustrated in Figures $1 \mathrm{~A}$ and $1 \mathrm{~B}$.

Substantial improvement of the symptoms and elimination of both objective and subjective measures of OSA following the correction of two specific dentofacial anomalies, such as maxillary constriction by rapid maxillary expansion, and mandibular retrognathia by functional jaw orthopedics in children justify/ explain the implicatory role of malocclusion in the pathogenesis of OSA. ${ }^{20-23}$

\section{Associative Relationships between Malocclusion and Obstructive Sleep Apnea}

The associative mechanism between skeletal malocclusion pattern and OSA has been widely discussed and explored in different populations, with myriad studies demonstrating high associations, and only few reporting weaker or nil associations between the two. As regards to prevalence of malocclusion in 5-10-year-old Vancouver's pediatric population with SDB, Pliska et al. ${ }^{24}$ did not find a significant prevalence of skeletal malocclusion. The reported percentage frequency of maxillary constriction (posterior crossbite) and mandibular retrognathia were $15.5 \%$ and $4.8 \%$ of the sample, respectively.

In a cross-sectional investigation involving 604 subjects under 18 years of age, Huynh et al. ${ }^{19}$ found no significant associations of anteroposterior mandibular deficiencies with reported pediatric OSA
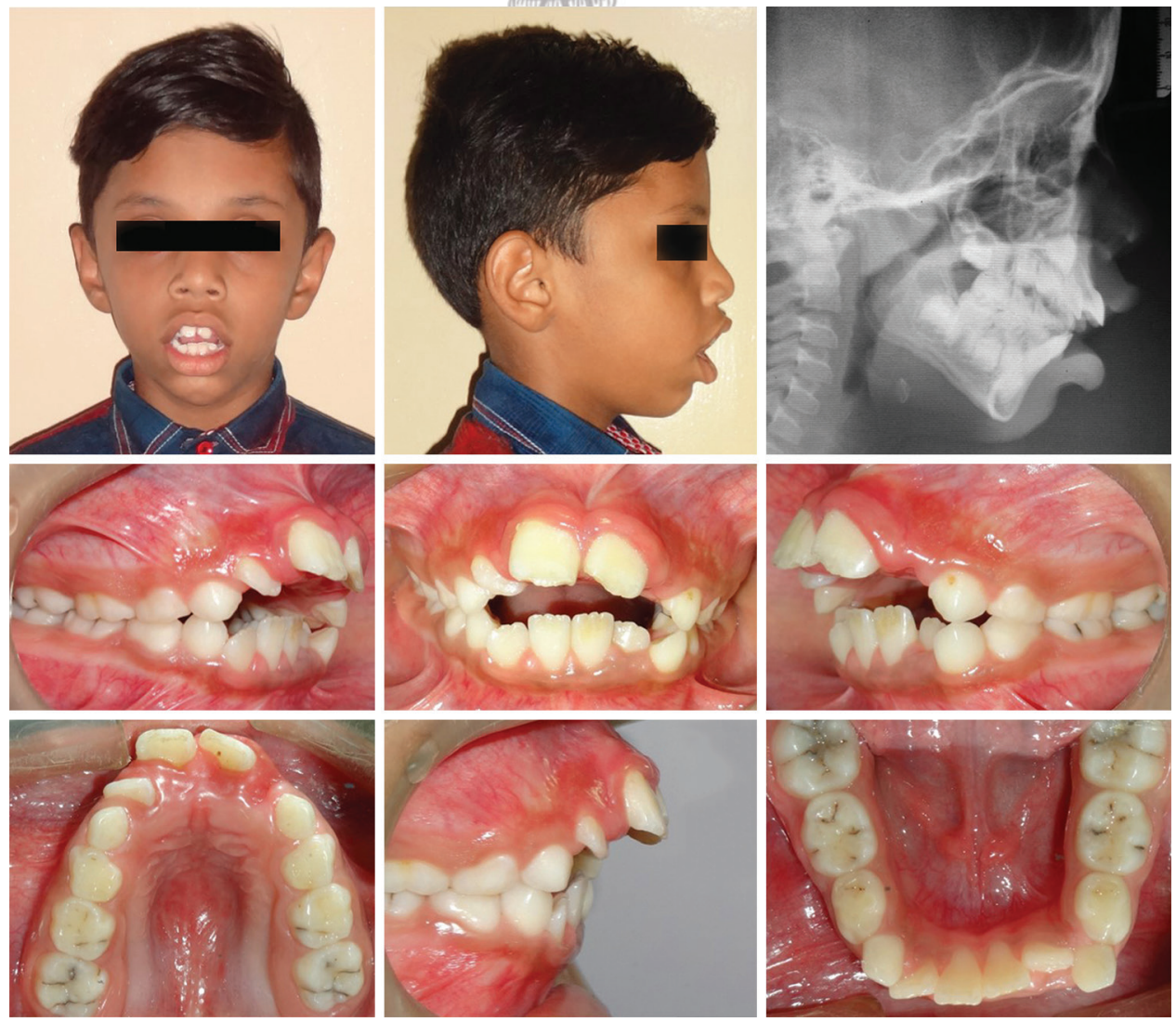

Fig. 1A: Class II division 1 malocclusion with anterior-open bite and excessive facial convexity in a seven-year old patient seeking orthodontic treatment for protruded teeth 


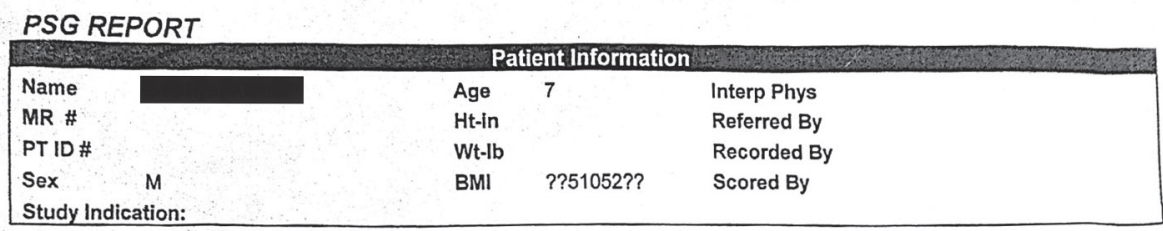

Polysomnography was conducted on the night of 5/30/2018. The following were monitored: central and occipital EEG. electrooculogram (EOG), submentalis EMG, nasal and oral airfow, thoracic and abdominal wall motion, anterior tibialis EMG, body position and electrocardiogram. Arterial oxygen saturation was monitored with a pulse oximeter. The tracing was scored using 30 second epochs. Hypopneas were scored per AASM definition VII4.B (3\% desaturation).

\begin{tabular}{|c|c|c|c|c|}
\hline Lights Out: & $=10: 24: 46 \mathrm{PM}$ & Stage & Duration & $\%$ TST \\
\hline Lights On: & $\rightarrow 8: 06: 40 \mathrm{AM}$ & N1 & $17.0 \mathrm{~min}$ & $3.8 \%$ \\
\hline Total Recording Time: & $581.9 \mathrm{~min}$ & N2 & $156.0 \mathrm{~min}$ & $35.2 \%$ \\
\hline Total Sleep Time (TST): & $443.0 \mathrm{~min}$ & N3 & $270.0 \mathrm{~min}$ & $60.9 \%$ \\
\hline Sleep Period Time: & $\rightarrow .556 .0 \mathrm{~min}$ & $\mathrm{R}$ & $0.0 \mathrm{~min}$ & $0.0 \%$ \\
\hline Sleep Onset: & $10: 45: 46 \mathrm{PM}$ & & & \\
\hline Sleep Efficiency: & $.76 .1 \%$ & \multicolumn{3}{|c|}{ Latencies From Lights Out z From Sleep Onset } \\
\hline Sleep Latency (from LOff): & $21.0 \mathrm{~min}$ & N1 & $21.0 \mathrm{~min}$ & $0.0 \mathrm{~min}$ \\
\hline R Latency (from Sleep Onset): & N/A & N2 & $22.0 \mathrm{~min}$ & $1.0 \mathrm{~min}$ \\
\hline Wake After Sleep Onset (WASO): & $117.9 \mathrm{~min}$ & N3 & $21.5 \mathrm{~min}$ & $0.5 \mathrm{~min}$ \\
\hline Wake During Sleep: & $113.0 \mathrm{~min}$ & $\mathrm{R}$ & N/A & N/A \\
\hline Total Wake Time: & $138.9 \mathrm{~min}$ & & & \\
\hline \% Wake Time: & 23.9 & & & \\
\hline
\end{tabular}

$\%$ Wake Time: 23.9

\begin{tabular}{|c|c|c|c|c|c|c|c|c|}
\hline \multicolumn{9}{|c|}{ 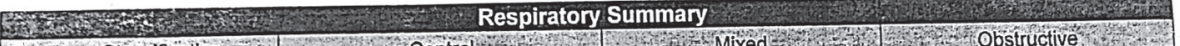 } \\
\hline \multirow{2}{*}{ By: Event Classification } & SWentral & 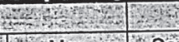 & 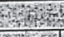 & Mixed: & & & Obstructi & Ve. \\
\hline & I Mean & \begin{tabular}{|c|l} 
Max & Co \\
\end{tabular} & ount & Mean : & $M \mathrm{Max}^{\prime}$ & Count & t- Mean & Max \\
\hline \multirow{3}{*}{$\begin{array}{l}\text { Apneas, NREM } \\
\text { Apneas, REM } \\
\text { Apneas, Total }\end{array}$} & 35.4 & 126.0 & 1 & 11.0 & 11.0 & 0 & 0.0 & 0.0 \\
\hline & & & & & & & 150 & 20.0 \\
\hline & 35.4 & 126.0 & 1 & 11.0 & $\frac{11.0}{\text { rdesaturati }}$ & tion. & 15.0 & \\
\hline \multirow{4}{*}{$\begin{array}{l}\text { Hypopneas, NREM } \\
\text { Hypopneas, REM } \\
\text { Hypopneas, Total }\end{array}$} & "Hypopneas & scored based on & $3 \%$ or & greater & r desaturati & Ion. & 0.0 & 0.0 \\
\hline & 17.6 & 33.5 & & RERAs & S, NREM & 0 & & 0.0 \\
\hline & & & & RERAs & s, REM & 0 & 0.0 & 0.0 \\
\hline & 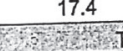 & $\frac{33.5}{3+5.8}$ & & RERAs & S. Total & rousalis & 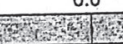 & 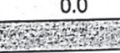 \\
\hline Event Statistics & Count & Total & & oftitits & Gount & 36. & Index & \\
\hline Apneas, Total & 8 & 1.1 & & & 0 & & 0.0 & \\
\hline $\begin{array}{l}\text { Hypopneas, Total } \\
\text { Apnea + Hypopnea Total }\end{array}$ & 21 & 2.8 & & & 7 & & 0.9 & \\
\hline Apnea + Hypopnea Total & 29 & AHI: 3.9 & & & 7 & & 0.9 & \\
\hline \multirow{2}{*}{$\begin{array}{l}\text { Apnea + Hypopnea NREM } \\
\text { Apnea + Hypopnea REM }\end{array}$} & 26 & AHI: 3.5 & & & 5 & & 0.7 & \\
\hline & & AHI: N/A & & & 0 & & 0.0 & \\
\hline \multirow{2}{*}{$\begin{array}{l}\text { RERAs, Total } \\
\text { Total Events }(A+H+R E R A) \text { Total }\end{array}$} & 0 & 0.0 & & & 0 & & 0.0 & \\
\hline & 29 & RDI: 3.9 & & & 7 & & 0.9 & \\
\hline \multirow{2}{*}{$\begin{array}{l}\text { Total Events }(\mathrm{A}+\mathrm{H}+\mathrm{RERA}) \text { NREM } \\
\text { Total Events }(\mathrm{A}+\mathrm{H}+\mathrm{RERA}) \text { REM }\end{array}$} & 26 & RDI: 3.5 & & & $\begin{array}{l}5 \\
0\end{array}$ & & $\begin{array}{l}0.7 \\
0.0\end{array}$ & \\
\hline & & RDI: N/A & & & 0 & & & \\
\hline
\end{tabular}

Total Events (A+H+RERA) REM
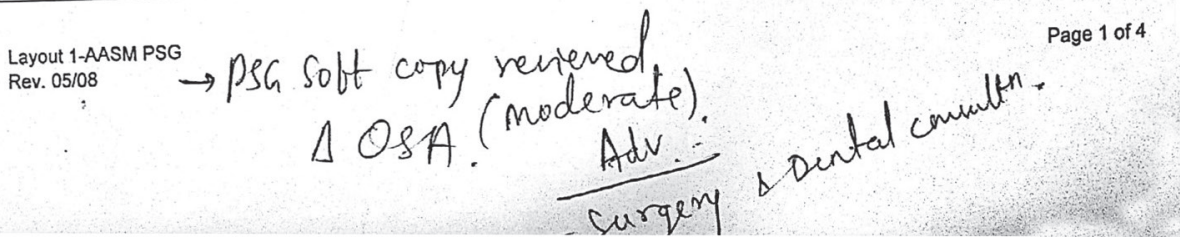

Fig. 1B: Polysomnographic report of the child showing moderate grade OSA

symptoms when compared with other subjects. However, a retrusive mandible and overjet showed significant association with morning headaches, tooth grinding and clenching in pediatric OSA patients.

Miyao et al., ${ }^{15}$ were one of the foremost researchers who studied the maxillofacial bone features, including the role of malocclusion in non-obese Japanese adult male patients with OSA using cephalometric and dental model analyses. They concluded that patients with class II malocclusion exhibited higher apneahypopnea index with severe overjet being a significant factor (greater than $6 \mathrm{~mm}$ ) closely associated with severity of apneahypopnea index $(\mathrm{AHI})$ in non-obese OSA patients. The overall prevalences of severe overjet and deep overbite (i.e., the vertical overlap of the upper incisor teeth over the lower incisors when the opposing posterior teeth are in contact) (greater than $6 \mathrm{~mm}$ ) were
$43.3 \%$ and $26.8 \%$, respectively. Variables such as age, the angle of protrusion of the maxillary alveolar base (SNA), the difference in angle of protrusion between the maxillary and mandibular alveolar bases (ANB), thickness of the airway behind the soft palate (PAS), mandibular plane to hyoid $(\mathrm{Mp}-\mathrm{H})$, distance between posterior nasal spine and tip of the soft palate (PNS-P), overbite, and overjet did not show any significant differences between non-obese $\left(\mathrm{BMI}<25 \mathrm{~kg} / \mathrm{m}^{2}\right)$ and obese obstructive sleep apnea syndrome (OSAS) patients. However, a significantly smaller angle of protrusion of the mandibular alveolar base (SNB) reflected a greater role of mandibular retrusion in non-obese than in obese OSAS patients.

Similarly, influential role of abnormal maxillofacial features such as a small mandible and maxilla, and a retroposition mandible in the genesis of obstructive apnea/hypopnea events during sleep in 
non-obese OSAS patients (with a small neck diameter) have also been shown in a cluster analysis conducted by Tsuchiya et al. ${ }^{25}$ (using cephalometry and CT images of 84 patients with OSAS). In addition to body weight, Hou et al. ${ }^{26}$ also identified lower posterior facial height, mandibular body length, craniocervical extension, and sella-hyoid distance as the significant predictive variables for OSA in Chinese male subjects. The craniocervical angle, representing both head posture and cervical vertebral compensatory changes, has also been shown to be a useful diagnostic or monitoring measurement in OSA subjects. Ang et al. ${ }^{27}$ reported a more caudal hyoid bone position and greater craniocervical angulation in Chinese OSA patients.

Comparative studies ${ }^{28-30}$ between Asian and Caucasian OSA populations have shown increased severity of OSA at lower levels of obesity, thereby suggesting that restrictive features of craniofacial morphology such as shorter, steeper anterior cranial base, smaller maxilla, and smaller and retropositioned mandible, are important predisposing risk factors for OSA in Asians compared to Caucasians. The skeletal craniofacial morphology has also been shown to play a major etiological role in $62 \%$ of nonobese Asian OSA population as compared to soft-tissue morphology. ${ }^{31} \mathrm{~A}$ meta-analysis by Miles et al. $^{32}$ showed that among all the craniofacial risk variables, mandibular body length is the strongest risk factor exhibiting greater associations with OSA.

Johal and Conaghan ${ }^{33}$ assessed the role of maxillary morphology in the etiology of OSA using cephalometrics and study model measurements. More obtuse palatal angle in male OSA subjects, shorter PNS-posterior pharyngeal wall distance and longer soft palate in female OSA subjects were significant findings of the study. Smaller anteroposterior facial dimensions, mandibular retrognathia with shorter mandibular body length, and a significantly shorter distance from the posterior pharyngeal wall to the lingual surface of their lower incisors were found to be significant contributing factors in OSA. Both males and females demonstrated significantly reduced minimum palatal airway widths. The authors also found that palatal height measurement at the level of the first premolar, second premolar, and molar was a reliable indicator of maxillary constriction. These findings were contrary to the findings of Cistulli et al., ${ }^{34}$ and Seto et al., ${ }^{13}$ who observed no significant differences in palatal heights between OSA and control subjects.

Pertaining to the role of soft-tissue causative factors in Caucasians; a larger soft palate, an increased soft palate length, a smaller pharynx, and a larger tongue size have been shown to contribute significantly to the development of OSA. ${ }^{35}$ On the contrary, similar analysis in a Japanese sample, however, did not reveal greater soft tissue volumes in OSA patients; although significantly restricted mandibular dimensions were observed in these patients. ${ }^{36}$

\section{Ethnic Variability of Risk Factors}

Sutherland et al. ${ }^{7}$ theorized that the contributions of upper airway soft tissues, craniofacial bony dimensions, and obesity risk factors may show variability along with differences in predominant primary pathophysiology between ethnic groups. Owing to issues such as complex and heterogeneous nature of population groups, variation in measurements, definitions of OSA, variable contribution of facial structure, ethnicity and control groups, intra-ethnic study designs present inherent difficulties in extrapolating inter-ethnic differences in OSA craniofacial morphology. However, common features associated with craniofacial morphology in OSA in both Caucasian and Asian populations predominantly include the inferior positioning of the hyoid bone, retropositioning of the mandible, a smaller cranial base and an increase in the craniocervical extension angle.

\section{Epidemiologic Panorama of Malocclusion in Relation to Obstructive Sleep Apnea}

Skeletal class II pattern usually results from maxillary prognathism, mandibular retrognathism or hypoplasia, or any combination of the two, resulting in a convex profile. The main underlying problem in skeletal class II patients with OSA is the posteriorly-oriented or underdeveloped mandible which results in displacement of the soft tissues attached to it, impinging on the airway space and adversely affecting the airway patency. ${ }^{37}$

With respect to the frequency distribution of classes II and III skeletal relationships, Johal et al., ${ }^{33}$ and Seto et al. ${ }^{13}$ observed no significant differences between OSA and control subjects. However, significant differences in facial profile shape and malocclusion class in adult Malay subjects with and without OSA were reported in a study by Banabilh et al., ${ }^{38}$ who investigated the association of facial profile shape, malocclusion class, and palatal morphology with OSA in these subjects. The frequency of class II malocclusion was highest among the OSA group at $51.7 \%$, followed by that of class I at $35 \%$ and class III at $13.3 \%$. A convex facial profile (71.7\%) and V-shaped palatal vault (53.3\%) were other frequent findings in OSA patients. Similarly, increased prevalence of class II malocclusion (26.3\%) with mandibular retrognathia (19.7\%) among Brazilian OSA patients has also been reported in a study by Zonato et al. ${ }^{39}$ Capistrano et al. also showed that class II and brachyfacial morphological patterns exhibit greater apnea and hypopnea index (AHI) as compared to class III skeletal patterns. ${ }^{40}$

Indian adults with OSA exhibit variations in dental arch morphology when compared to similar age and gender-matched normal subjects. High prevalence of malocclusions in relation to the molar/canine region has been reported in the OSA group, with $60 \%$ of the OSA subjects demonstrating an Angle's class II malocclusion. ${ }^{41}$

Furthermore, a critical evidence-based appraisal by Patel and Nagle ${ }^{42}$ substantiated the consistent role of class II malocclusion in the etiopathogenesis of OSA disorder. Considering the multifactorial causes of OSA, it has also been reported that higher incidence of OSA appears to be associated with classes I and II malocclusions. ${ }^{43}$ Roedig et al. ${ }^{44}$ reported greater associations of skeletal Class II phenotypes with the development of OSA, irrespective of individual's BMI.

Very recently, the frequent occurrence of "silent" OSA has also been observed in patients with dentofacial deformities (DFD). ${ }^{45}$ The greater prevalence of OSA was found in bimaxillary DFD involving the chin and chronic obstructive nasal breathing when compared with the general adult population. The mandibular deficiency and short face patterns were most commonly affected by silent OSA. ${ }^{45}$ An example of a severe skeletal class II malocclusion with asymmetric dentofacial deformity and excessive facial convexity in an adult patient with long-standing bilateral TMJ ankylosis, contributing to severe OSA is depicted in Figures $2 \mathrm{~A}$ and $\mathrm{B}$.

In pediatric OSA patients, increased prevalence of Class II molar relationship, i.e., $29.3 \%$ as compared to $4.9 \%$ in the non-OSA control group has also been reported by Pirilä-Parkkinen et al. ${ }^{18}$ Studies reporting the increased number of pediatric OSA patients having a class II malocclusion provide the basis for explanation of occurrence of increased overjet in them. ${ }^{46-48}$ Craniofacial skeletal variables such as mandibular retrognathia are supposed to have moderate to high genetic contributions. ${ }^{49}$ On the contrary, occlusal variables, such as molar relationship, exhibit minimal familial associations. Hence, the increased frequency of class II malocclusion 

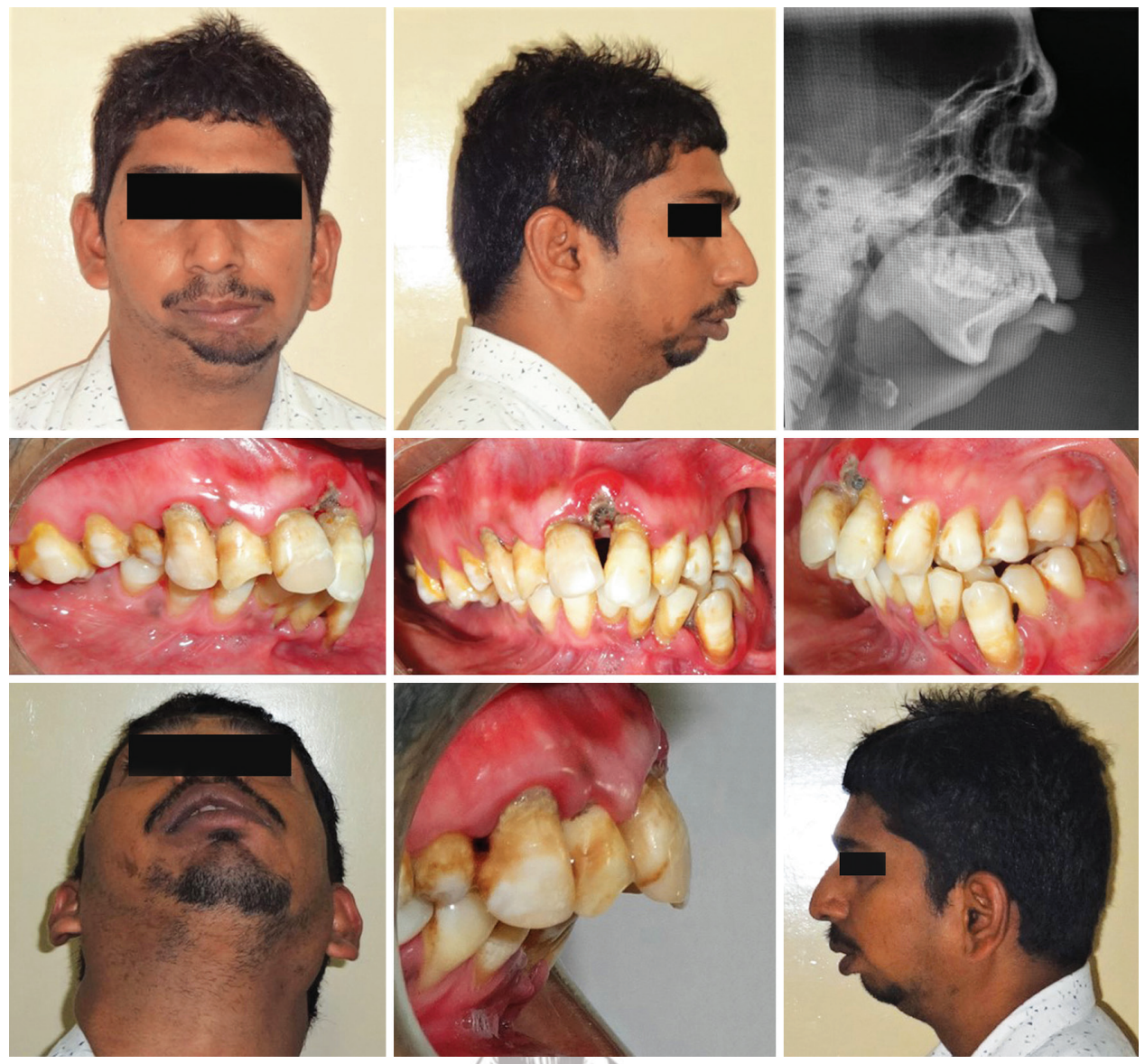

Fig. 2A: Severe asymmetric Class II dentofacial deformity due to long-standing bilateral TMJ ankylosis in an adult patient seeking intervention for nil mouth opening, periodontally compromised dentition and severe OSA

in OSA patients may be explained by environmental factors. ${ }^{49}$ For instance, the development of a class II malocclusion in OSA can be attributed to the extended head position attained as an overactive compensation mechanism for a narrow retroglossal airway. The prolonged head and cervical column extension usually affect the mandibular rest position, thereby causing mandibular retrusion and increased overjet. ${ }^{50}$

Concerning the variations in dental arch dimensions as related to OSA, children with diagnosed OSA exhibit narrower maxillary dental arches, increased overjet, reduced overbite, shorter mandibular dental arch length and mandibular crowding when compared with the non-OSA control children. ${ }^{18}$ The characteristic features of skeletal open bite such as posteriorly inclined mandible and increased lower anterior facial height were also observed in pediatric OSA patients with anterior open bite (AOB). ${ }^{51}$ Strong associations of mandibular crowding and $A O B s$ with increased severity of OSA, have also been reported in literature.

The occurrence of constricted maxillary arch width in children with OSA has been attributed to following factors: (i) mouth breathing and an altered position of the tongue, which disturbs the muscular equilibrium between the tongue and the cheeks, ${ }^{18}$ and (ii) a prolonged supine sleeping position which is related to $\mathrm{AHI}$ in OSA patients. ${ }^{52}$ It has been postulated that a prolonged supine sleeping position in young children (up to 10 years of age) correlates with reduced intermaxillary width, while prolonged head extension during sleep correlates inversely with the overjet. ${ }^{50}$ Due to nasopharyngeal airway obstruction in
OSAS-patients, tongue assumes a more anterior position in an attempt to secure a free airway passage, thereby resulting in increased lingual pressure on the dental arches. Consequently, the increase in dental arch dimensions was observed, particularly in children with the highest apnea index (Al) scores $(>4) .{ }^{50}$ Maeda et al. ${ }^{53}$ have also found that maxillary dental arch constriction related to anteroposterior skeletal discrepancy rather than maxillary skeletal constriction is a contributory variable of malocclusion in the development and aggravation of OSA in Japanese male adult OSA patients.

The associations between OSA and craniofacial morphology in children that can be explained by the connection between the mode of breathing and postural changes have not been clearly elucidated. In a systematic review and meta-analysis of the craniofacial morphological characteristics in children with OSAS, Flores-Mir et al. ${ }^{54}$ reported that dentoskeletal abnormalities consistent with pediatric OSAS such as retrusive chin, steep mandibular plane, and class II malocclusion with vertical/hyperdivergent growth pattern should be considered as "red flags" or warning signs. Further detailed exploration by dentists (in particular, orthodontists) into the patients' medical histories is warranted in such cases to prevent further worsening and later transformed into a full-blown lifethreatening disorder. The authors argued that there was ambiguity regarding the role of a hyperdivergent class II malocclusion facial morphology in the development of OSA in children. They also questioned whether the genesis of altered craniofacial morphology could be due to altered growth response to OSAS. 


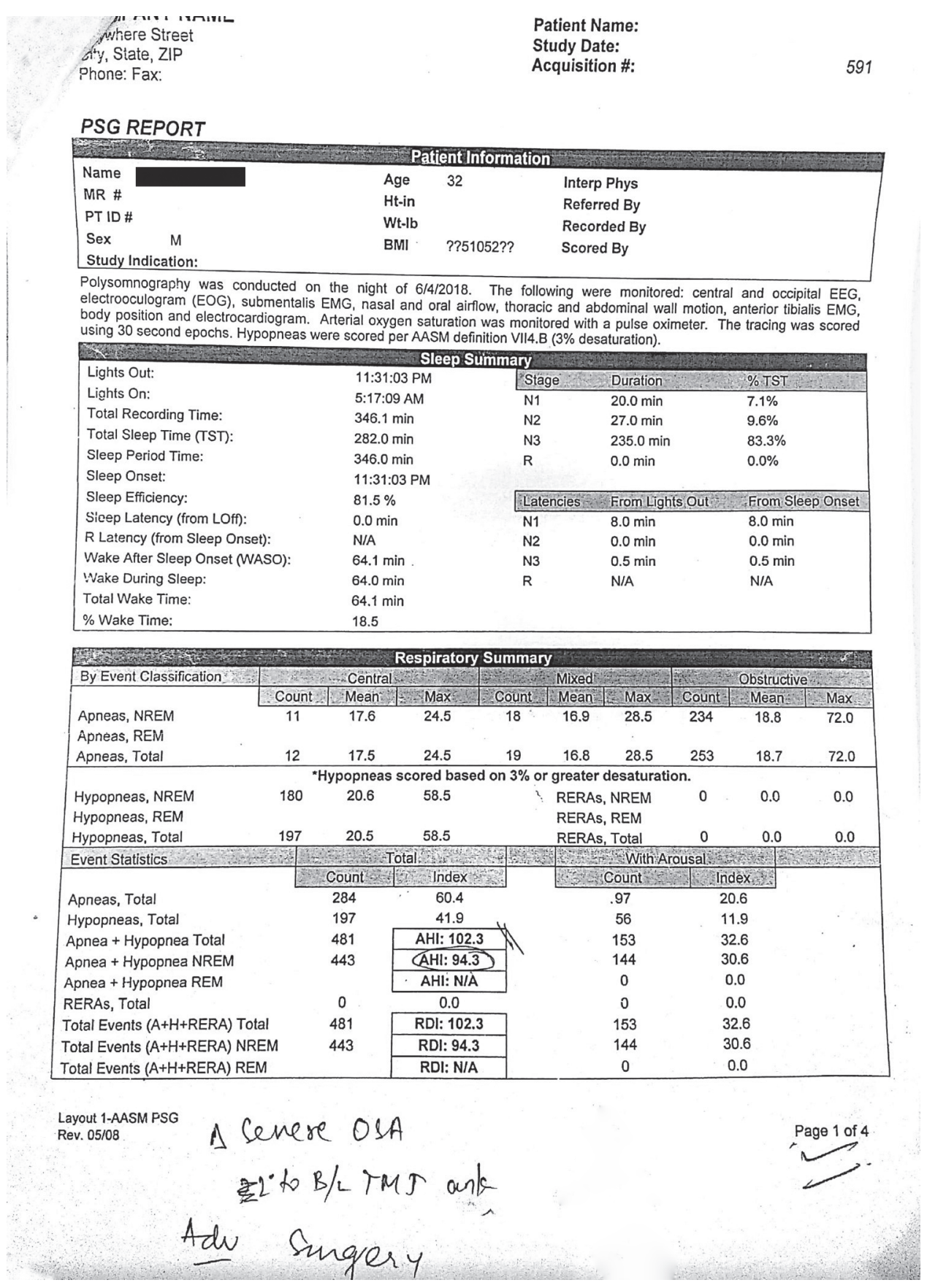

Fig. 2B: Severe OSA as confirmed with polysomnography

Nevertheless, in-depth knowledge and a better understanding of malocclusion as a risk factor in the pathophysiology of the disorder are imperative in identification and implementation of an appropriate individualized treatment plan based on scientific rationale, while taking into consideration the concerns and expectations of the patient. ${ }^{55}$

\section{SUMMARY}

The role of craniofacial morphology and malocclusion in OSA deserves special attention so that early recognition of the abnormal craniofacial morphology and developing malocclusion in its budding stage helps halt its further progression. Because of heterogenicity of the OSA afflicted populations, additional research focusing on ethnic variations in malocclusions and involving larger populations might be beneficial in the formulation of more meaningful and satisfying treatment plans and evaluating treatment outcomes in OSA populations.

\section{ACKnOWLedgment}

We would like to express our gratitude to Dr. Dipti Gothi, Professor, Department of Pulmonary Medicine, ESIPGIMSR, Basai Darapur, New Delhi, India for providing valuable inputs during compilation of the review.

\section{References}

1. Deatherage JR, Roden RD, Zouhary K. Normal Sleep Architecture. Semin Orthod 2009;15:86-87. 
2. McNicholas WT. Clinical diagnosis and assessment of obstructive sleep apnoea syndrome. Monaldi Arch Chest Dis 1997; 52:37-42.

3. Park JG, Ramar K, Olson EJ. Updates on Definition, Consequences, and Management of Obstructive Sleep Apnea. Mayo Clin Proc. 2011;86(6):549-555.

4. Al Lawati NM, Patel SR, Ayas NT. Epidemiology, risk factors, and consequences of obstructive sleep apnea and short sleep duration. Prog Cardiovasc Dis 2009;51:285-293.

5. American Academy of Sleep Medicine. The International Classification of Sleep Disorders: Diagnostic and Coding Manual. 2nd ed. Westchester (IL): American Academy of Sleep Medicine, 2005.

6. Bixler EO, Vgontzas AN, Lin H-M, Liao D, Calhoun S, Vela-Bueno A et al. Sleep disordered breathing in children in a general population sample: prevalence and risk factors. Sleep 2009;32(6):731-736.

7. Sutherland K, Lee RW, Cistulli PA. Obesity and craniofacial structure as risk factors for obstructive sleep apnoea: Impact of ethnicity. Respirology 2012;17:213-222.

8. Jureyda S, Shucard DW. Obstructive Sleep Apnea-An Overview of the Disorder and Its Consequences. Semin Orthod 2004;10:63-72.

9. Hudgel DW. The role of upper airway anatomy and physiology in obstructive sleep apnea. Clin Chest Med. 1992;13:383-398.

10. Banabilh SM, Suzina AH, Dinsuhaimi S, Samsudin AR, Singh GD. Craniofacial obesity in patients with obstructive sleep apnea. Sleep Breath. 2009;13:19-24.

11. Guilleminault C, Khramtsov A. Upper airway resistance syndrome in children: a clinical review. Semin Pediatr Neurol 2001;8:207-215.

12. Lyberg T, Krogstad O, Djupesland G.Cephalometric analysis in patients with obstructive sleep apnoea syndrome.:I. Skeletal Morphology. The Journal of Laryngology \& Otology. 1989 Mar;103(3):287-292.

13. Seto BH, Gotsopoulos H, Sims MR, Cistulli PA. Maxillary morphology in obstructive sleep apnoea syndrome. Eur J Orthod. 2001;23: 703-714.

14. Adachi S, Lowe AA, Tsuchiya M, Ryan CF, Fleetham JA. Genioglossus muscle activity and inspiratory timing in obstructive sleep apnea. Am J Orthod Dentofac Orthop 1993;104:138-145.

15. Miyao E, Noda A, Miyao M, Yasuma F, Inafuku S. The Role of Malocclusion in Non-obese Patients with Obstructive Sleep Apnea Syndrome. Intern Med 2008;47:1573-1578.

16. Ikävalko T, Tuomilehto H, Pahkala R, Tompuri T, Laitinen T, Myllykangas Ret al. Craniofacial morphology but not excess body fat is associated with risk of having sleep disordered breathing - the PANIC Study (a questionnaire-based inquiry in 6-8-year-olds). Eur J Pediatr. 2012; 171(12):1747-1752.

17. Zucconi M, Caprioglio A, Calori G, Ferini-Strambi L, Oldani A, Castronovo $\mathrm{C}$ et al. Craniofacial modifications in children with habitual snoring and obstructive sleep apnoea: a case control study. Eur Respir J. 1999;13(2):411-417.

18. Pirilä-Parkkinen $K$, Pirttiniemi $P$, Nieminen $P$, Tolonen $U$, Pelttari $\mathrm{U}$, Löppönen H. Dental arch morphology in children with sleep disordered breathing. Eur J Orthod. 2009;31(2):160-167.

19. Huynh NT, Morton PD, Rompré PH, Papadakis A, Remise C. Associations between sleep-disordered breathing symptoms and facial and dental morphometry, assessed with screening examinations. Am J Orthod Dentofac Orthop. 2011;140(6):762-770.

20. Schütz TCB, Dominguez GC, Hallinan MP, Cunha TCA, Tufik S. Class II correction improves nocturnal breathing in adolescents. The Angle Orthodontist 2011;81(2):222-228.

21. Zhang C, He H, Ngan P. Effects of twin block appliance on obstructive sleep apnea in children: a preliminary study. Sleep Breath. 2013;17(4):1309-1314.

22. Pirelli P, Saponara M, Guilleminault C. Rapid maxillary expansion in children with obstructive sleep apnea syndrome. Sleep 2004; 27(4): 761-766.

23. Villa MP, Rizzoli A, Miano S, Malagola C. Efficacy of rapid maxillary expansion in children with obstructive sleep apnea syndrome: 36 months of follow-up. Sleep Breath. 2011;15(2):179-184.

24. Pliska BT, Lee J, Chadha NK. Prevalence of malocclusion in children with sleep-disordered breathing. Journal of Dental Sleep Medicine. 2017;4(2):41-44.
25. Tsuchiya M, Lowe AA, Pae E, Freetham J. Obstructive sleep apnea subtypes by cluster analysis. Am J Orthod Dentofac Orthop 1992;533542:101.

26. Hou HM, Hagg U, Sam K, Rabie AB, Wong RW. Lam B et al. Dentofacial Characteristics of Chinese Obstructive Sleep Apnea Patients in Relation to Obesity and Severity. The Angle Orthodontist 2006;76: 962-969.

27. Ang PK, Andrew Sandham,Wan Cheng Tan. Craniofacial Morphology and Head Posture in Chinese Subjects With Obstructive Sleep Apnea. Semin Orthod 2004;10:90-96.

28. Liu Y, Lowe AA, Zeng X, Fu M, Fleetham JA. Cephalometric comparisons between Chinese and Caucasian patients with obstructive sleep apnea. Am. J. Orthod. Dentofacial Orthop. 2000;117:479-485.

29. Li KK, Kushida C, Powell NB, Riley RW, Guilleminault C. Obstructive sleep apnea syndrome: a comparison between Far-East Asian and white men. Laryngoscope 2000;110:1689-1693.

30. Lee RW, Vasudavan S, Hui DS, Prvan T, Petocz P, Darendeliler MA et al. Differences in craniofacial structures and obesity in Caucasian and Chinese patients with obstructive sleep apnea. Sleep 2010; 33: 1075-1080.

31. Vigg A, Vigg A, Vigg A. Obstructive sleep apnea in a referral population in India. Sleep 2010;33:1075-1080.

32. Miles PG, Vig PS,Weyant RJ, Forrest TD, Rockette HE Jr. Craniofacial structure and obstructive sleep apnea syndrome-a qualitative analysis and meta-analysis of the literature. Am J Orthod Dentofacial Orthop 1996;109:163-172.

33. Johal A, Conaghan C. Maxillary morphology in obstructive sleep apnea: A cephalometric and model study. Angle Orthod 2004;74: 648-656.

34. Cistulli PA, Richards GN, Palmisano RG, Unger G, Sullivan CE. Influence of maxillary constriction on nasal resistance and sleep severity in patients with Marfan's syndrome. Chest. 1996;110:1184-1193.

35. Johal A, Patel SI, Battagel JM: The relationship between craniofacial anatomy and obstructive sleep apnoea: A case controlled study. J Sleep Res 2007;16:319-326.

36. Okubo M, Suzuki M, Horiuchi A, Okabe S, Ikeda K, Higano S et al. Morphologic analyses of mandible and upper airway soft tissue by MRI of patients with obstructive sleep apnea hypopnea syndrome. Sleep 2006;29:909-915.

37. Conley RS, Legan HL. Correction of severe obstructive sleep apnea with bimaxillary transverse distraction osteogenesis and maxillomandibular advancement. Am J Orthod Dentofac Orthop. 2006;129:283-292.

38. Banabilh SM, Samsudin AR, Suzina AH, Dinsuhaimi S. Facial Profile Shape, Malocclusion and Palatal Morphology in Malay Obstructive Sleep Apnea Patients. Angle Orthod. 2010;80:37-42.

39. Zonato Al, Bittencourt LR, Martinho FL, Junior JF, Gregorio LC, Tufik $\mathrm{S}$. Association of systematic head and neck physical examination with severity of obstructive sleep apnea hypopnea syndrome. Laryngoscope. 2003;113:973-980.

40. Capistrano A, Cordeiro A, Capelozza Filho L, Almeida VC, Castro e Silva PI, Martinez $S$ et al. Facial morphology and obstructive sleep apnea. Dental Press J Orthod. 2015 Nov-Dec;20(6):60-67.

41. Nainan O, Jayan B, Mitra R, Ghosh S, Chopra SS, Mukherjee M. Dental Arch Morphology as a Predictor of Sleep Disordered Breathing. Sleep Hypn 2017;19(2):30-37

42. Patel N, Nagle M. Having An Angle Class II Malocclusion Is Associated With A Higher Incidence Of Obstructive Sleep Apnea: An EvidenceBased Synopsis. UTHSCSA CATs Library CAT \#2364. 2013

43. Banabilh SM. Orthodontic view in the diagnoses of obstructive sleep apnea. J Orthod Sci. 2017 Jul-Sep;6(3):81-85.

44. Roedig JJ, Phillips BA, Morford LA, Van Sickels JE, Falcao-Alencar G, Fardo DW, et al. Comparison of BMI, AHI, and apolipoprotein E $\varepsilon 4$ (APOE- $\varepsilon 4$ ) alleles among sleep apnea patients with different skeletal classifications. J Clin Sleep Med. 2014;10(4):397-402.

45. Posnick JC, Adachie A, Singh N, Choi E. "Silent" Sleep Apnea in Dentofacial Deformities and Prevalence of Daytime Sleepiness After Orthognathic and Intranasal Surgery. J Oral Maxillofac Surg 2018;76:833-843 
46. Kawashima S, Peltomäki T, Sakata H, Mori K, Happonen RP, Rönning O. Craniofacial morphology in preschool children with sleep-related breathing disorder and hypertrophy of tonsils. Acta Paediatrica 2002;91:71-77.

47. Shintani T, Asakura K, Kataura A. Evaluation of the role of adenotonsillar hypertrophy and facial morphology in children with obstructive sleep apnea. J Otorhinolaryngol Relat Spec. 1997;59: 286-291.

48. Guilleminault C, Stoohs R. Chronic snoring and obstructive sleep apnea syndrome in children. Lung 1990;168:912-919.

49. Harris EF, Johnson MG. Heritability of craniometric and occlusal variables: a longitudinal sib analysis. Am J Orthod Dentofacial Orthop 1991;99:258-268.

50. Pirila K, Tahvanainen $\mathrm{P}$, Huggare J, Nieminen $\mathrm{P}$, Lopponen $\mathrm{H}$. Sleeping positions and dental arch dimensions in children with suspected obstructive sleep apnea syndrome. Eur J Oral Sci.1995;103:285-291.
51. Zettergren-Wijk L, Forsberg CM, Linder-Aronson S. Changes in dentofacial morphology after adeno-/tonsillectomy in young children with obstructive sleep apnoea - a 5 year follow-up study. Eur J Orthod 2006;28:319-326.

52. Cartwright RD. Effect of sleep position on sleep apnea severity. Sleep 1984;7:110-114.

53. Maeda K, Tsuiki S, Fukuda T, Takise Y, Inoue Y. Is maxillary dental arch constriction common in Japanese male adult patients with obstructive sleep apnoea? Eur J Orthod 2014;36:403-408.

54. Flores-Mir C, Korayem M, Heo G, Witmans M, Major MP, Major PW. Craniofacial morphological characteristics in children with obstructive sleep apnea syndrome: A systematic review and metaanalysis. J Am Dent Assoc. 2013;144(3):269-277.

55. Maurya RK, Singh H, Mishra HA, Gupta A. Modified Interim Mandibular Advancement (MIMA) Appliance for Symptomatic Correction of Obstructive Sleep Apnea. J Clin Diagn Res 2016 Aug;10(8):ZH01-ZH03.

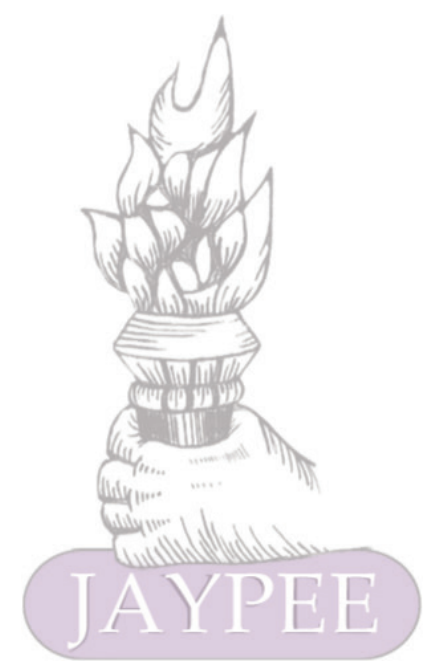

